Document downloaded from:

http://hdl.handle.net/10251/82254

This paper must be cited as:

Borràs-Ferrís, J.; Sánchez Tovar, R.; Blasco-Tamarit, E.; Fernández Domene, RM.; GarciaAnton, J. (2016). Effect of Reynolds number and lithium cation insertion on titanium anodization. Electrochimica Acta. 196:24-32. doi:10.1016/j.electacta.2016.02.160.

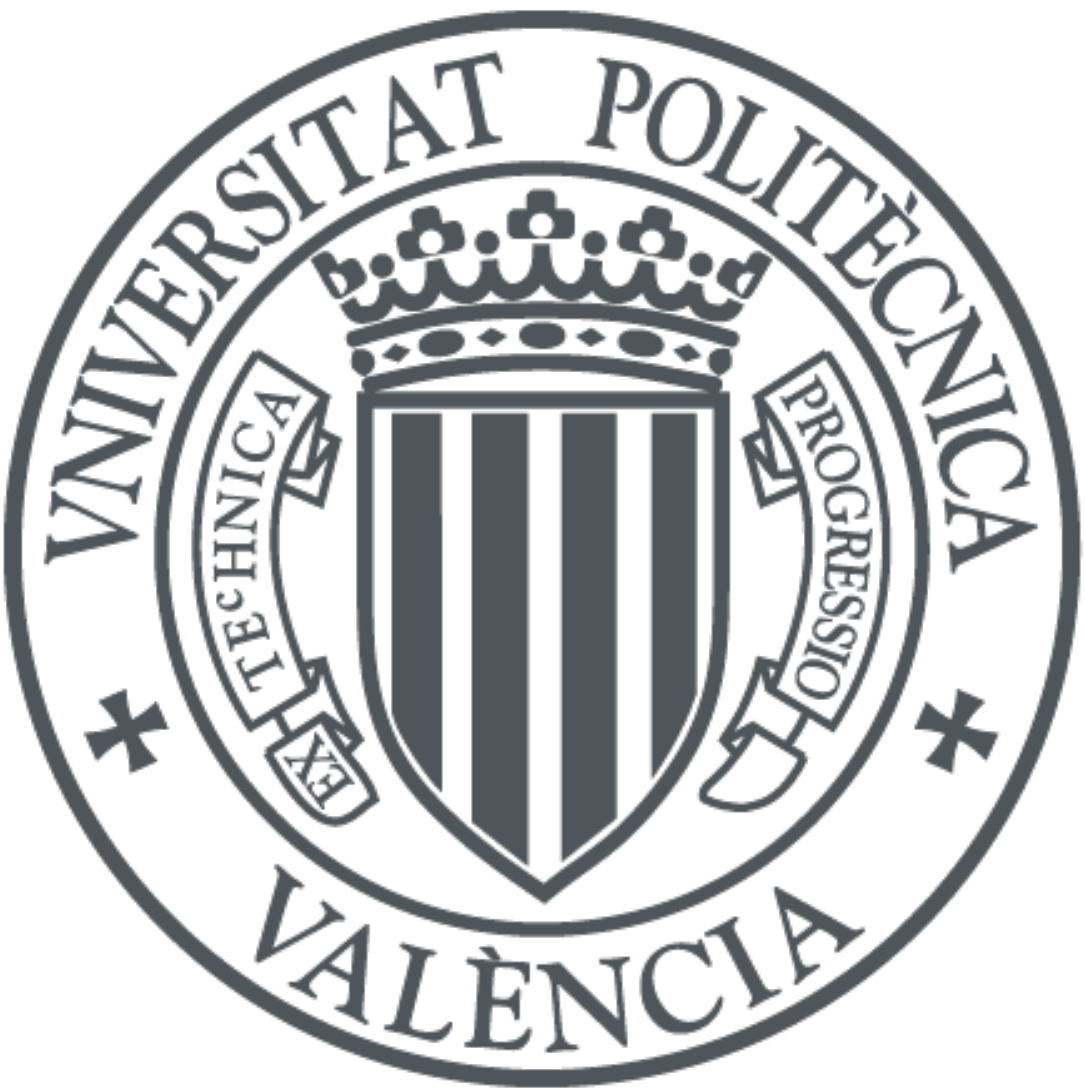

The final publication is available at

http://doi.org/10.1016/j.electacta.2016.02.160

Copyright Elsevier

Additional Information 


\title{
Effect of Reynolds number and lithium cation insertion on titanium anodization
}

J. Borràs-Ferrís ${ }^{\mathrm{a}}$, R. Sánchez-Tovar ${ }^{\mathrm{a}}$, E. Blasco-Tamarit ${ }^{\mathrm{a}}$, R.M. Fernández-Domene ${ }^{\mathrm{a}}$,

\author{
J. García-Antón ${ }^{\text {a* }}$ \\ angeniería Electroquímica y Corrosión (IEC). Departamento de Ingeniería Química y \\ Nuclear. ETSI Industriales. Universitat Politècnica de València. Camino de Vera s/n, \\ 46022 Valencia, Spain.
}

Tel. 34-96-387 76 32, Fax. 34-96-387 76 39, e-mail: jgarciaa@iqn.upv.es

\begin{abstract}
This work studies the influence of using hydrodynamic conditions (Reynolds number, $\mathrm{Re}=0$ to $\mathrm{Re}=600$ ) during $\mathrm{Ti}$ anodization and $\mathrm{Li}^{+}$intercalation on anatase $\mathrm{TiO}_{2}$ nanotubes. The synthesized photocatalysts were characterized by using Field Emission Scanning Electron Microscope (FE-SEM), Raman Confocal Laser Microscopy, Electrochemical Impedance Spectroscopy (EIS), Mott-Schottky analysis (M-S), photoelectrochemical hydrogen production and resistance to photocorrosion tests. The obtained results showed that the conductivity of the NTs increases with $\mathrm{Li}^{+}$intercalation and Re. The latter is due to the fact that the hydrodynamic conditions eliminate part of the initiation layer formed over the tube-tops, which is related to an increase of the photocurrent in the photoelectrochemical water splitting. Besides, the photogenerated electron-hole pairs are facilitated by $\mathrm{Li}^{+}$intercalation. Finally, this work confirms that there is a synergistic effect between $\mathrm{Re}$ and $\mathrm{Li}^{+}$intercalation.
\end{abstract}

Keywords: $\mathrm{TiO}_{2}$ nanotubes; hydrodynamic conditions; water splitting; electrochemical impedance spectroscopy (EIS); Mott-Schottky analysis. 


\section{Introduction}

In recent years, nanotube (NT) arrays based on transition-metal oxides are gaining interest in a wide field of applications, such as in dye-sensitized solar cells [1, 2], photocatalysis [3-7] and biomedicine [8]. Among all transition-metal oxides, $\mathrm{TiO}_{2}$ is the most extensively studied material due to its unique properties. Especially, in photocatalytic reactions, $\mathrm{TiO}_{2}$ is used as a photocatalyst due to its high stability and semiconductor abilities capable of generating charge by absorbing energy [9-13]. Besides, its suitable band-edge positions make possible the photoelectrochemical water splitting [14] (using solar energy) into $\mathrm{H}_{2}$ and $\mathrm{O}_{2}$ to generate hydrogen, the potential fuel of the future.

In order to achieve a high surface area and consequently, to enhance the photocatalytic activity, $\mathrm{TiO}_{2}$ is synthesized in the form of nanotube arrays [15]. Nowadays, $\mathrm{TiO}_{2}$ nanotubes are synthesized by several methods, including sol-gel transcription $[16,17]$, hydrothermal processes $[18,19]$ and anodization of titanium in fluoride-based electrolytes $[20,21]$. The latter is the most promising because it allows obtaining highly ordered nanotube arrays, and their dimensions (length, diameter, and tube wall) can be precisely controlled [22].

In order to carry out the anodization two types of electrolytes can be used: aqueousbased or organic-based. Organic electrolytes are the most used because these electrolytes result in highly ordered longer tubes $[23,24]$. Nevertheless, the nanotubes formed in organic electrolytes show an "initiation layer" over the tube tops, which blocks the nanotube arrays and therefore the solar energy absorption is reduced $[22,25]$. 
Nowadays, several methods are investigated to remove this "initiation layer", such as mild sonication [23] and hydrodynamic conditions applied during anodization with a rotating electrode configuration [22]. The latter has the advantage of removing the "initiation layer" in the same process of anodization and, therefore, other independent processes in order to remove this layer are not needed. Moreover, the use of hydrodynamic conditions can significantly affect on the final $\mathrm{TiO}_{2}$ nanotube geometry $[22,26,27]$. After anodization, an amorphous structure is obtained which implies the presence of a high number of defects. These defects act as recombination centers and a thermal treatment is required in order to convert the amorphous structure into a crystalline one [28].

On the other hand, the efficiency of $\mathrm{TiO}_{2}$ nanotubes is limited by its wide intrinsic band gap of $\approx 3.2 \mathrm{eV}$ for $\mathrm{TiO}_{2}$ in anatase phase $[29,30]$. Thus, the usable fraction of the solar spectrum which can be exploited is only 5\% [31]. In this way, the process of inserting impurities in the $\mathrm{TiO}_{2}$ NTs is widely used for the purpose of modulating their electrical properties (doping), thus, the efficiency of $\mathrm{TiO}_{2} \mathrm{NTs}$ might be increased. Recently, several works $[28,32,33]$ studied the $\mathrm{Li}^{+}$cation insertion into $\mathrm{TiO}_{2}$ lattice and they obtained a drastic change in electronic properties, such as a highly increase in the conductivity of $\mathrm{TiO}_{2}[32,33]$. However, these studies were made in static electrolyte and the influence of hydrodynamic conditions during the anodization process was not evaluated.

In this work, we investigate the synergistic effect between Reynolds number (Re) and $\mathrm{Li}^{+}$cation insertion in the $\mathrm{TiO}_{2}$ lattice in order to optimize the photoelectrochemical water splitting for hydrogen production. To characterize the nanostructures, different 
microscopy techniques have been used: Field Emission Scanning Electron Microscope (FE-SEM) and Raman Confocal Laser Microscopy. Additionally electrochemical techniques: Electrochemical Impedance Spectroscopy (EIS) and Mott-Schottky technique (M-S), as well as photoelectrochemical techniques have been also used.

\section{Experimental procedure}

Anodization was carried out using Teflon coated titanium rod ( $8 \mathrm{~mm}$ in diameter, 99.3 $\%$ purity) as the working electrode, i.e. $0.5 \mathrm{~cm}^{2}$ were exposed to the electrolyte. On the other hand, a platinum mesh was used as the counter electrode. Prior to anodization, titanium surface was abraded with 220 to 4000 silicon carbide (SiC) papers and degreased by sonication in ethanol for 2 minutes. The samples were then mounted in a rotating electrode to perform the anodization under hydrodynamic conditions using a voltage source. Different Reynolds numbers were used: 0, 200, 400 and 600, which correspond to $0,1728,3456$ and $5185 \mathrm{rpm}$. Anodization was performed in ethylene glycol, $1 \mathrm{M} \mathrm{H}_{2} \mathrm{O}$ and $0.05 \mathrm{M} \mathrm{NH}_{4} \mathrm{~F}$ electrolytes at $55 \mathrm{~V}$ during 30 minutes. Current density during anodization was measured versus time. After each test, the titanium rod was sliced to characterize the morphology of the obtained nanostructures by using Field Emission Scanning Electron Microscopy (FE-SEM). In order to transform amorphous $\mathrm{TiO}_{2}$ to an anatase phase structure, the anodized samples were annealed at $450{ }^{\circ} \mathrm{C}$ for 1 hour. The crystalline microstructure of $\mathrm{TiO}_{2}$ was examined by means of a Raman Confocal Laser microscopy. For these measurements, a $632 \mathrm{~nm}$ neon laser with $420 \mu \mathrm{W}$ was used. 
In order to add $\mathrm{Li}^{+}$to the obtained nanostructures (doped-nanostructures), samples were immersed in an $1 \mathrm{M} \mathrm{LiClO}_{4}$ solution, applying $-1.5 \mathrm{~V}_{\mathrm{Ag} / \mathrm{AgCl}}$ during 3 seconds. In this way, $\mathrm{Ti}^{+4}$ was reduced to $\mathrm{Ti}^{+3}$ and, at the same time, $\mathrm{Li}^{+}$was intercalated into the $\mathrm{TiO}_{2}$ lattice. In order to perform the $\mathrm{Li}^{+}$intercalation, a three electrode electrochemical cell was used. The $\mathrm{TiO}_{2}$ NTs after annealing served as the working electrode, while a $\mathrm{Ag} / \mathrm{AgCl}(3 \mathrm{M} \mathrm{KCl})$ electrode was the reference electrode, and a platinum tip was the counter electrode.

For the electrochemical and photoelectrochemical water splitting tests, an electrochemical cell with the same electrodes and electrode configuration than the used for doping the samples, was employed. The area of the $\mathrm{TiO}_{2}$ nanostructures (working electrode) exposed to the test solution was $0.13 \mathrm{~cm}^{2}$. The electrochemical measurements were conducted in a $0.1 \mathrm{M} \mathrm{Na}_{2} \mathrm{SO}_{4}$ solution using an Autolab PGSTAT302N potentiostat under dark conditions (without irradiation). EIS experiments were conducted at the open circuit potential (OCP) over a frequency range from $100 \mathrm{kHz}$ to $10 \mathrm{mHz}$ with a $10 \mathrm{mV}$ (peak to peak) signal amplitude. Mott-Schottky plots were subsequently obtained by sweeping the potential from the OCP in the negative direction at $10 \mathrm{mV} \mathrm{s}^{-1}$ with an amplitude signal of $10 \mathrm{mV}$ at a frequency value of $10 \mathrm{kHz}$.

The photoelectrochemical experiments were carried out under simulated sunlight condition AM $1.5\left(100 \mathrm{~mW} \mathrm{~cm}^{2}\right)$ in a $1 \mathrm{M} \mathrm{KOH}$ solution. Photocurrent vs. voltage characteristics were recorded by scanning the potential from $-0.8 \mathrm{~V}_{\mathrm{Ag} / \mathrm{AgCl}}$ to $+0.55 \mathrm{~V}_{\mathrm{Ag} / \mathrm{AgCl}}$ with a scan rate of $2 \mathrm{mV} \mathrm{s}^{-1}$. Photocurrent transients as a function of the applied potential were recorded by chopped light irradiation (60 s in the dark and $20 \mathrm{~s}$ in 
the light). Samples were left at $+0.55 \mathrm{~V}_{\mathrm{Ag} / \mathrm{AgCl}}$ in the light for one hour, in order to evaluate their stability against photocorrosion.

\section{Results and discussion}

\subsection{Current density transients during anodization}

The growth of the $\mathrm{TiO}_{2}$ nanotubes was monitored by recording the current density during anodization. Figure 1 shows that all the samples present three stages. Firstly, in stage I, current density decreases because a compact oxide layer $\left(\mathrm{TiO}_{2}\right)$ is formed on titanium $[25,34]$. Then, in the second stage (stage II), current density increases due to the fact that fluoride ions present in the electrolyte attack the formed $\mathrm{TiO}_{2}$ layer, which results in water-soluble $\left[\mathrm{TiF}_{6}\right]^{2-}$ species. Thus, the current density increases as the reactive area also increases [25, 35]. Finally, in the third stage (stage III), current density remains almost constant due to the formation and growth of regular nanotubes $[25,26]$.

The slope corresponding to stage II is different depending on the Reynolds number. Figure 1 shows that the curves of anodization under hydrodynamic conditions show a higher positive slope in stage II compared to the one obtained at $\operatorname{Re}=0$. This confirms that diffusion process is favoured due to hydrodynamic conditions. Moreover, since the slope corresponding to stage II increases until Re 400 and it remains almost constant for Re 600, it can be said that hydrodynamic conditions favour the fluoride ions diffusion until $\operatorname{Re} 400$ (the highest increase being obtained between $\operatorname{Re} 0$ and $\operatorname{Re} 200$ ). 


\subsection{Field Emission Scanning Electron Microscopy (FE-SEM)}

Figures 2, 3 and 4 show the morphology of the samples obtained by electrochemical anodization of $\mathrm{TiO}_{2}$ under static and hydrodynamic conditions by using a FE-SEM microscope. A porous $\mathrm{TiO}_{2}$ layer can be observed over the nanotubes, i.e. an initiation layer (Figures 2a and 2b). This initiation layer blocks the nanotubes preventing part of the solar radiation from being absorbed at the photoelectrode. Figure $\mathbf{2 b}$ clearly shows the top of the tubes in delimited areas since parts of the initiation layer was removed. Besides, hydrodynamic conditions applied during anodization mainly affect on three parameters related to the morphology of the nanostructures: the length of the nanotubes, the initiation layer and the thickness of the nanotubes. Figure $2 \mathbf{c}$ shows that selforganized $\mathrm{TiO}_{2}$ nanotubes were formed. On the other hand, variations on the morphology after $\mathrm{Li}^{+}$intercalation were not observed (not shown in Figure 2).

Figure 2d shows the influence of Reynolds number on the length of the nanotubes. The length is higher as the Reynolds number increases. This effect involves an increase of the surface area available for the photocatalytic reactions.

Figure 3 shows the top view of the nanostructures using FE-SEM. It is important to point out that in Figure 3a $(\operatorname{Re}=0)$ there is a continuous initiation layer, however, this layer begins to detach in certain delimitated areas as hydrodynamic conditions increase (Figure 3b, 3c and 3d, corresponding to Re from 200 to 600).

On the other hand, Figure 4 shows that in those areas where the initiation layer is still attached, an increase in the average diameter of the porous presented in the initiation layer is observed when hydrodynamic conditions are applied in relation to static 
conditions (Figure 4a, $\mathbf{4 b}$ and $\mathbf{4 c}$ ). Therefore, the entrances of the real tubes become more accessible. Finally, Figure $4 \mathbf{d}$ shows a decrease of the thickness of $\mathrm{TiO}_{2}$ nanotubes as hydrodynamic conditions increase, which might reduce the electron-hole recombination process.

\subsection{Raman Confocal Laser Microscopy}

Evaluation of the crystallinity of the as-prepared and annealed (doped and undoped) $\mathrm{TiO}_{2}$ nanotubes was carried out by means of Raman Confocal Laser Microscopy. Figure 5 shows, as an example, the Raman Spectra of the as prepared, undoped and doped nanotubes anodized at $\operatorname{Re} 600$, since no differences were found in the Raman Spectra regardless of the Re used during anodization.

The crystallinity of the $\mathrm{TiO}_{2}$ nanotubes is evaluated according to the peaks presented in the Raman spectra. Anatase phase shows four peaks in the spectra at roughly 141.7, 396.2, 515.1 and $639.3 \mathrm{~cm}^{-1}$ [36-38]. In Figure 5 it can be observed that the as-prepared $\mathrm{TiO}_{2}$ nanotubes are characterized by a spectra without peaks, which is in agreement with an amorphous phase. However, annealed (doped and undoped) $\mathrm{TiO}_{2}$ nanotubes present four characteristics peaks, which correspond to the peaks of the anatase phase. This confirms that annealing at $450{ }^{\circ} \mathrm{C}$ for 1 hour, generates $\mathrm{TiO}_{2}$ nanotubes with anatase phase. Moreover, the peaks obtained for the annealed, both undoped and doped NTs, are almost the same. Therefore, it can be concluded that there are no significant variations on the crystalline structure after $\mathrm{Li}^{+}$intercalation. 


\subsection{EIS measurements}

From Figure 6a, it is possible to discern that undoped $\mathrm{TiO}_{2}$ NTs have higher impedance values than the doped $\mathrm{TiO}_{2}$ NTs. Besides, among the undoped samples, $\mathrm{TiO}_{2} \mathrm{NTs}$ synthesized at Re 0 possess the highest impedance. Bode-phase plots, (Figure 6b), show two unfinished semicircles for the samples anodized at $\operatorname{Re} 0, \operatorname{Re} 200$ and $\operatorname{Re} 400$ without $\mathrm{Li}^{+}$intercalation, which correspond to the presence of two time constants. However, for the nanotubes synthesized at $\mathrm{Re} 600$ without $\mathrm{Li}^{+}$and for all the doped samples, the Bode-phase plots show only one semicircle due to the superposition of the two time constants. The two time constants can be attributed to the formation of the nanotubular layer on top of the compact $\mathrm{TiO}_{2}$ layer $[39,40]$. On the other hand, Bodemodulus plots in Figure 6c show a decrease of impedance modulus as hydrodynamic conditions increase at low and intermediate frequencies. Moreover, $\mathrm{Li}^{+}$insertion also involves a decrease in the impedance modulus for the same frequency range. Additionally, the impedance at high frequencies in Bode plots corresponds to the resistance of the electrolyte which possesses similar values regardless the Reynolds number and the doping conditions.

EIS experimental data were fitted to an electrical equivalent circuit. The electrical equivalent circuit proposed is shown in Figure $\mathbf{6 d}$ and it is formed by a resistive 
element $\left(R_{s}\right)$, corresponding to the electrolyte resistance, and two groups of resistances and constant phase elements (R-CPE), corresponding to the nanotubular layer $\left(\mathrm{R}_{1^{-}}\right.$ $\left.\mathrm{CPE}_{1}\right)$ and the compact $\mathrm{TiO}_{2}$ layer $\left(\mathrm{R}_{2}-\mathrm{CPE}_{2}\right)[15,40]$. This electrical equivalent circuit has been already used by other authors. Constant phase elements (CPEs) have been used instead of pure capacitors to account for frequency dispersion and non-ideality. Then, CPEs have been converted into pure capacitances $(\mathrm{C})$ by using the following equation $[41,42]:$

$$
\mathrm{C}=\frac{(\mathrm{Q} \cdot \mathrm{R})^{1 / \alpha}}{\mathrm{R}}
$$

where $\mathrm{Q}$ is the impedance of the CPE and $\mathrm{R}$ corresponds to $\mathrm{R}_{2}$ when $\mathbf{e q} \mathbf{1}$ is used to calculate $\mathrm{C}_{2}$. However, in order to determine $\mathrm{C}_{1}, \mathrm{R}$ is calculated according to eq $\mathbf{2}$.

$$
\frac{1}{\mathrm{R}}=\frac{1}{\mathrm{R}_{\mathrm{S}}}+\frac{1}{\mathrm{R}_{1}}
$$

Table 1 shows the values of the different parameters which characterize the electrical equivalent circuit. $R_{S}$ has similar values for all the studied conditions (between 32-42 $\Omega$ ), since the resistance of the electrolyte remains almost constant. Besides, $R_{2}$ is higher than $\mathrm{R}_{1}$ regardless of the hydrodynamic and doping conditions because the nanotubular layer has higher surface area than the compact $\mathrm{TiO}_{2}$ layer, i.e., the nanotubes possess a higher conductivity. On the other hand, the CPE constant, $\alpha$, lies between -1 (pure inductance) and +1 (pure capacitor) [43]. In this work the $\alpha$ values are between 0.5 and 1 which are in agreement with a non-ideal capacitive behavior. Table 1 shows that $\alpha_{1}$ takes values lower than $\alpha_{2}$ for all the nanostructures. This confirms that the $\mathrm{TiO}_{2}$ nanotubes layer is more heterogeneous in comparison to the compact $\mathrm{TiO}_{2}$ layer, the latter having a behavior similar to an ideal capacitor. 
Table 1 also shows that $\mathrm{R}_{1}$ decreases as Reynolds number increases for the undoped and doped nanotubes, indicating that $\mathrm{TiO}_{2}$ NTs formed at higher hydrodynamic conditions possess higher conductivities than nanotubes formed at $\operatorname{Re}=0$. Moreover, $\mathrm{C}_{2}$ values increase as the Reynolds number increases (regardless the doping conditions), indicating that the thickness of the compact $\mathrm{TiO}_{2}$ layer decreases, which can be interpreted as a transition from a mostly compact layer to a nanotubular one [40]. Concerning the influence of $\mathrm{Li}^{+}$insertion, it can be observed that $\mathrm{R}_{1}$ decreases significantly when the $\mathrm{TiO}_{2}$ nanotubes are doped. This fact can be explained by a higher number of controlled defects due to $\mathrm{Li}^{+}$intercalation and, therefore, the conductivity is favored.

\subsection{Mott-Schottky analysis}

The Mott-Schottky analysis is a common tool used for the characterization of the electrochemical capacitance of the semiconductor/electrolyte interface as a function of the applied potential [44]. The Mott-Scottky equation predicts a linear relationship of $C_{S C}{ }^{-2}$ with the applied potential $(U)$, as described by the following equation for an ntype semiconductor [40, 45-47]:

$$
\frac{1}{\mathrm{C}_{\mathrm{SC}}{ }^{2}}=\left(\frac{2}{e \cdot \varepsilon_{0} \cdot \varepsilon_{r} \cdot N_{D}}\right) \cdot\left(U-U_{F B}-\frac{k \cdot T}{e}\right)
$$

where $N_{D}$ is the donor density, $\varepsilon_{0}\left(8.85 \cdot 10^{-14} \mathrm{~F} / \mathrm{cm}\right)$ the vacuum permittivity, $\varepsilon_{r}$ the dielectric constant, $e$ the electron charge $\left(1.60 \cdot 10^{-19} \mathrm{C}\right), U_{F B}$ the flatband potential, $k$ the Boltzmann constant $\left(1.38 \cdot 10^{-23} \mathrm{~J} / \mathrm{K}\right)$ and $\mathrm{T}$ is the absolute temperature. The dielectric constant varies depending on the $\mathrm{Li}^{+}$intercalation, this parameter takes values of 100 for the undoped $\mathrm{TiO}_{2}$ NTs $[48,49]$ and a value of 500 is assumed for doped $\mathrm{TiO}_{2}$ 
NTs [31]. In fact, Van de Krol claimed that the increase in the dielectric constant may be originated by an increase in the polarizability of the $\mathrm{TiO}_{2}$ from the intercalated $\mathrm{Li}^{+}$ cations [45].

Figure 7 shows the Mott-Schottky plots for the undoped and doped $\mathrm{TiO}_{2}$ nanotubes anodized from $\operatorname{Re} 0$ to $\operatorname{Re} 600$. The results given in Figure 7 were obtained at the frequency of $10 \mathrm{kHz}$ in dark conditions, since at this high frequency value the capacitances do not depend on the frequency [50, 51]. Figure 7 shows that the capacitance values are higher for the doped $\mathrm{TiO}_{2} \mathrm{NTs}$ (lower values of $\mathrm{C}_{\mathrm{SC}}{ }^{-2}$ ). In this way, a magnification of the Mott-shottky doped plots have been performed as an inset in Figure 7, in order to show the straight lines presented in the doped samples.

Table 2 shows the donor densities determined from the positive slopes of the straight lines in the Mott-Schottky plots using eq 3. It can be observed that the donor density notably increases for the doped samples (two orders of magnitude) compared to the undoped ones. The increase in the donor density might be associated with an increase in the number of defects present in the $\mathrm{TiO}_{2}$ nanotubes due to the $\mathrm{Li}^{+}$intercalation. Thus, these defects improve the charge transfer along the nanotubes (this is in agreement with the results obtained by means of EIS, Table 1). Concerning to the influence of hydrodynamic conditions, it is possible to observe that the donor density increases, to some extent, as Reynolds number also increases for the undoped samples. This fact indicates that, although the morphology of the $\mathrm{TiO}_{2}$ nanostructures did not change with Re (i.e, nanotubes were formed in all cases), a higher number of oxygen vacancies and/or $\mathrm{Ti}^{3+}$ interstitials were introduced within the $\mathrm{TiO}_{2} \mathrm{NTs}$ structure when anodizing under hydrodynamic conditions. On the other hand, the influence of hydrodynamic 
conditions in the donor density for the doped samples is not clear $\left(N_{D}\right.$ varies between 1 and $4 \times 10^{21} \cdot \mathrm{cm}^{-3}$ ). This might be due to the high influence of the $\mathrm{Li}^{+}$insertion that hinders the influence of hydrodynamic conditions.

On the other hand, Table 2 also shows the $U_{F B}$ values obtained from the intercept of the straight line with the potential axis. The flatband potential is the potential that needs to be applied to the semiconductor to reduce the band bending to zero. Additionally, this electrochemical parameter is related to the potential drop at the depletion space charge layer $\left(U_{S C}\right)$ and the applied external potential $(U)$ [15], according to eq 4.

$$
U_{S C}=U-U_{F B}
$$

where $U_{S C}$ is the driving force to separate the photogenerated electron-hole pairs (charge separation). Thus, according to eq $\mathbf{4}$, in order to favor the charge separation, the flatband potential should be high and negative. Table 2 shows that flatband potential is more negative for the doped $\mathrm{TiO}_{2} \mathrm{NTs}$ than for the undoped ones, which indicates that the charge separation is favored by $\mathrm{Li}^{+}$intercalation.

\subsection{Photocurrent measurements}

Figure 8a shows the photoelectrochemical water splitting tests carried out under simulated sunlight AM 1.5 conditions for the different samples. Regardless of the doping condition, photocurrent densities increase with Reynolds number. This is in agreement with the EIS and M-S measurements (lower $\mathrm{R}_{1}$ values and higher $N_{D}$ for higher Re) and FE-SEM images. The high photocurrent densities obtained for the nanostructures anodized at higher Reynolds numbers are related to an increase in the conductivity of the NTs, due to a higher density of defects within their structure, which 
favors the current flow $[15,52]$. These high photocurrent densities obtained for samples anodized under hydrodynamic conditions are also directly related to an increase in the active area of the nanotubes exposed to the electrolyte with increasing Re. As shown in the FESEM images (Figures 2, 3 and 4), hydrodynamic conditions during anodization resulted in longer nanotubes lengths and larger diameters of the nanoporous initiation layer, as well as in a partial removal of the nanoporous initiation layer. It is important to point out that the partial removal of the initiation layer at higher Re contributes to an increase in the photocurrent densities in the water splitting tests. This fact is observed in Figure 8b, where the photoresponse of $\mathrm{TiO}_{2} \mathrm{NTs}$ of the same length $(\sim 6.2 \mu \mathrm{m})$, but anodized at different Re, are compared. The only difference between both samples is that the initiation layer of the sample synthesized at $\mathrm{Re}=600$ was partially removed during the anodization process. Therefore, photocurrent densities increased with increasing $\mathrm{Re}$ due to the higher active area of the nanotubes in contact with the electrolyte and due to a slightly increase in the number of defects (Table 2). On the other hand, photocurrent densities for $\mathrm{Li}^{+}$doped nanotubes are significantly higher than the values obtained for the undoped samples, which can be ascribed to their higher number of defects and flatband potentials (in absolute value) (Table 2). Therefore, there is a better charge transfer and transport in the doped nanotubes.

Additionally, Figure 8a shows that the photocurrents under illumination increase with the applied potential. According to eq 4, the potential drop at the depletion space charge layer increases when the potential applied is higher, thus, the charge separation is favored. Moreover, the photocurrent density increases with the applied potential until a potential value of $-0.3 \mathrm{~V}$ for the undoped $\mathrm{TiO}_{2} \mathrm{NTs}$, whereas the photocurrent increases in the entire range of potential, for the doped $\mathrm{TiO}_{2} \mathrm{NTs}$. This means that the undoped 
$\mathrm{TiO}_{2}$ NTs are saturated more easily by means of the potential applied in comparison to the doped $\mathrm{TiO}_{2}$ NTs.

On the other hand, in order to evaluate the stability of the NTs against photocorrosion they were tested under $\mathrm{AM} 1.5$ illumination at $0.55 \mathrm{~V}_{\mathrm{Ag} / \mathrm{AgCl}}$ during 1 hour. Figure 8c shows that the formed NTs were stable since the photocurrents generated in the process of water splitting were constant during the tests.

The synergistic effect between hydrodynamic conditions and $\mathrm{Li}^{+}$intercalation was studied using the photocurrent densities. Figure 8d shows that the combined effect ( Re + Doping) is higher than the sum of the individual effects obtained at $0.55 \mathrm{~V}_{\mathrm{Ag} / \mathrm{AgCl}}$. This synergistic effect between the hydrodynamic conditions and the $\mathrm{Li}^{+}$doping arises from the higher active areas of the samples anodized at $\operatorname{Re}>0$ (as shown in Figures 2, 3 and 4), thus enhancing the intercalation of $\mathrm{Li}^{+}$into the $\mathrm{TiO}_{2}$ nanotubes structure.

\section{Conclusions}

This work studied the influence of hydrodynamic conditions applied during anodization, as well as the $\mathrm{Li}^{+}$intercalation into $\mathrm{TiO}_{2}$ lattice in order to increase the photocurrent response in the photoelectrochemical water splitting.

The FE-SEM images show that the influence of hydrodynamic conditions results in an elimination of part of the initiation layer and in an increase of the length of the NTs. These facts involve a higher photocurrent density as Reynolds number increases. 
On the other hand, Raman Confocal Laser Microscopy revealed that $\mathrm{TiO}_{2}$ nanotubes in anatase phase were obtained after annealing at $450^{\circ} \mathrm{C}$ during 1 hour. Besides, the $\mathrm{Li}^{+}$ intercalation does not lead to significant variations on the crystalline structure.

EIS measurements showed that the resistance of the undoped NTs decreases with Re. On the other hand, concerning the $\mathrm{Li}^{+}$insertion, the resistance of the doped $\mathrm{TiO}_{2}$ nanotubes decreases due to a higher number of defects, which was confirmed in the M$\mathrm{S}$ analysis. Besides, M-S analysis showed an increase in the flatband potential (in absolute value) for the doped samples, therefore the photogenerated electron-hole pairs are favored. These results explain the higher photocurrent obtained for the doped samples in the photoelectrochemical water splitting.

The synthesized $\mathrm{TiO}_{2}$ nanotubes were stable in the test electrolyte under illumination.

A synergistic effect between the hydrodynamic conditions and $\mathrm{Li}^{+}$was found to arise from the higher active areas of the samples anodized at $\mathrm{Re}>0$, thus enhancing the intercalation of $\mathrm{Li}^{+}$into the $\mathrm{TiO}_{2}$ nanotubes structure.

Acknowledgements: Authors would like to express their gratitude for their financial support to the Ministerio of Economía y Competitividad (Project CTQ2013-42494-R).

\section{REFERENCES}

[1] B. O’Regan, M. Grätzel. A low-cost, high-efficiency solar cell based on dyesensitized colloidal $\mathrm{TiO}_{2}$ films, Nature 353 (1991) 737-740.

[2] P. Roy, D. Kim, K. Lee, E. Spiecker, P. Schmuki. $\mathrm{TiO}_{2}$ nanotubes and their application in dye-sensitized solar cells, Nanoscale 2 (2010) 45-59. 
[3] A. Fujishima, T.N. Rao, D.A. Tryk. Titanium dioxide photocatalysis, J. Photochem. Photobiol. C-Photochem. Rev. 1 (2000) 1-21.

[4] A. Fujishima, X. Zhang, D.A. Tryk. $\mathrm{TiO}_{2}$ photocatalysis and related surface phenomena, Surf. Sci. Rep. 63 (2008) 515-582.

[5] K. Maeda, K. Domen. Photocatalytic Water Splitting: Recent Progress and Future Challenges, J. Phys. Chem. Lett. 1 (2010) 2655-2661.

[6] J.H. Park, S. Kim, A.J. Bard. Novel carbon-doped TiO2 nanotube arrays with high aspect ratios for efficient solar water splitting, Nano Lett. 6 (2006) 24-28.

[7] J.M. Macak, M. Zlamal, J. Krysa, P. Schmuki. Self-organized TiO2 nanotube layers as highly efficient photocatalysts, Small 3 (2007) 300-304.

[8] J. Park, S. Bauer, K. Von Der Mark, P. Schmuki. Nanosize and vitality: TiO2 nanotube diameter directs cell fate, Nano Lett. 7 (2007) 1686-1691.

[9] M.R. Hoffmann, S.T. Martin, W. Choi, D.W. Bahnemann. Environmental Applications of Semiconductor Photocatalysis, Chem. Rev. 95 (1995) 69-96.

[10] V.F. Stone, R.J. Davis. Synthesis, characterization and photocatalytic activity of titania and niobia mesoporous molecular sieves, Chem. Mater. 10 (1998) $1468-1474$.

[11] M. Adachi, Y. Murata, M. Harada, S. Yoshikawa. Formation of Titania Nanotubes with High Photo-Catalytic Activity, Chem. Lett. 8 (2000) 942-943.

[12] T. Sreethawong, Y. Suzuki, S. Yoshikawa. Photocatalytic evolution of hydrogen over nanocrystalline mesoporous titania prepared by surfactantassisted templating sol-gel process, Catal. Commun. 6 (2005) 119-124.

[13] C.C. Tsai, J.N. Nian, H. Teng. Mesoporous nanotube aggregates obtained from hydrothermally treating $\mathrm{TiO}_{2}$ with $\mathrm{NaOH}$, Appl. Surf. Sci. 253 (2006) 18981902.

[14] I. Paramasivam, H. Jha, N. Liu, P. Schmuki. A Review of Photocatalysis using Self-organized $\mathrm{TiO}_{2}$ Nanotubes and Other Ordered Oxide Nanostructures, small 8 (2012) 3073-3103.

[15] R. Sánchez-Tovar, R. M. Fernández-Domene, D. M. García-García, J. GarcíaAntón. Enhancement of photoelectrochemical activity for water splitting by controlling hydrodynamic conditions on titanium anodization, J. Power Sources 286 (2015) 224-231.

[16] T. Kasuga, M. Hiramatsu, A. Hoson, T. Sekino and K. Niihara. Formation of Titanium Oxide Nanotube, Langmuir 14 (1998) 3160-3163.

[17] J. H. Jung, H. Kobayashi, K. J. C. Van Bommel, S. Shinkai, T. Shimizu. Creation of novel helical ribbon double-layered nanotube $\mathrm{TiO}_{2}$ structures using an organogel template, Chem. Mater. 14 (2002) 1445-1447. 
[18] D. V. Bavykin, J. M. Friedrich, F. C. Walsh. Protonated titanates and TiO2 nanostructured materials: synthesis, properties, and applications, Adv. Mater. 18 (2006) 2807-2824.

[19] D. V. Bavykin, V. N. Parmon, A. A. Lapkin, F. C. Walsh. The effect of hydrothermal conditions on the mesoporous structure of $\mathrm{TiO} 2$ nanotubes, J. Mater. Chem. 14 (2004) 3370-3377.

[20] V. Zwilling, E. Darque-Ceretti, A. Boutry-Forveille, D. David, M. Y. Perrin, M. Aucouturier. Structure and physicochemistry of anodic oxide films on titanium and TA6V alloy, Surf. Interface Anal. 27 (1999) 629-637.

[21] J. M. Macak, H. Tsuchiya, P. Schmuki. High-Aspect-Ratio $\mathrm{TiO}_{2}$ Nanotubes by Anodization of Titanium, Angew. Chem. Int. Ed. 44 (2005) 2100-2102.

[22] R. Sánchez-Tovar, I. Paramasivam, K. Lee, P. Schmuki. Influence of hydrodynamic conditions on growth and geometry of anodic $\mathrm{TiO}_{2}$ nanotubes and their use towards optimized DSSCs, J. Mater. Chem. 22 (2012) 1279212795 .

[23] T. T. Isimjan, S. Rohani, A. K. Ray. Photoelectrochemical water splitting for hydrogen generation on highly ordered $\mathrm{TiO}_{2}$ nanotubes fabricated by using $\mathrm{Ti}$ as cathode, Int. J. Hydrogen Energ. 37 (2012) 103-108.

[24] Paulose M, Prakasam HE, Varghese OK, Peng L, Popat KC, Mor GK, et al. $\mathrm{TiO} 2$ nanotube arrays of $1000 \mathrm{~mm}$ length by anodization of titanium foil: phenol red diffusion, J. Phys. Chem. C 111 (2007) 14992-14997.

[25] P. Roy, S. Berger, P. Schmuki. $\mathrm{TiO}_{2}$ Nanotubes: Synthesis and Applications, Angew. Chem. Int. Ed. 50 (2011) 2904-2939.

[26] R. Sánchez-Tovar, K. Lee, J. García-Antón, P. Schmuki. Formation of anodic $\mathrm{TiO}_{2}$ nanotube or nanosponge morphology determined by the electrolyte hydrodynamic conditions, Electrochem. Commun. 26 (2013) 1-4.

[27] R. Sánchez-Tovar, K. Lee, J. García-Antón, P. Schmuki. Photoelectrochemical poperties of anodic $\mathrm{TiO}_{2}$ nanosponge layers, ECS Electrochem. Lett. 2 (2013) 9-11.

[28] A. Ghicov, P. Schmuki. Self-ordering electrochemistry: a review on growth and functionality of $\mathrm{TiO}_{2}$ nanotubes and other self-aligned $\mathrm{MO}_{\mathrm{x}}$ structures, Chem. Commun. 20 (2009) 2791-2808.

[29] R. Beranek, H.Tsuchiya, T. Sugishima, J.M. Macak, L. Taveira, S. Fujimoto, H. Kisch, P. Schmuki. Enhancement and limits of the photoelectrochemical response from anodic TiO2 nanotubes, Appl. Phys. Lett. 87 (2005) 243114243114-3.

[30] H. Tsuchiya, J. M. Macak, A. Ghicov, A. S. Räder, L. Taveira, P. Schmuki. Characterization of electronic properties of $\mathrm{TiO}_{2}$ nanotube films, Corrosion Sci. 49 (2007) 203. 
[31] L. k. Tsui, M. Saito, T. Homma, G. Zangari. Trap-state passivation of titania nanotubes by electrochemical doping for enhanced photoelectrochemical performance, J. Mater. Chem. A 3 (2015) 360-367.

[32] R. Hahn, A. Ghicov, H. Tsuchiya, J. M. Macak, A. G. Muñoz, P. Schmuki. Lithium-ion insertion in anodic $\mathrm{TiO}_{2}$ nanotubes resulting in high electrochromic contrast, Phys. Status Solidi A 204 (2007) 1281-1285.

[33] J. M. Macak, B. G. Gong, M. Hueppe, P. Schmuki. Filling of $\mathrm{TiO}_{2}$ Nanotubes by Self-Doping and Electrodeposition, Adv. Mater. 19 (2007) 3027-3031.

[34] K. Shankar, G. K. Mor, H. E. Prakasam, S. Yoriya, M. Paulose, O. Varghese, C. A. Grimes. Highly-ordered $\mathrm{TiO}_{2}$ nanotube arrays up to $220 \mathrm{~mm}$ in length: use in water photoelectrolysis and dye-sensitized solar cells, Nanotechnology 18 (2007) 065707 (11pp).

[35] D. Regonini, C. R. Bowen, A. Jaroenworaluck, R. Stevens. A review of growth mechanism, structure and crystallinity of anodized $\mathrm{TiO}_{2}$ nanotubes, Mater. Sci. Eng. R 74 (2013) 377-406.

[36] Leonardo L. Costa, Alexandre G.S. Prado. TiO2 nanotubes as recyclable catalyst for efficient photocatalytic degradation of indigo carmine dye, J. Photochem. Photobiol. A-Chem. 201 (2009) 45-49.

[37] P.T. Hsiao, K.P. Wang, C.W. Cheng, H.S. Teng. Nanocrystalline Anatase $\mathrm{TiO}_{2}$ Derived from a Titanate-Directed Route for Dye-Sensitized Solar Cells, J. Photochem. Photobiol. A 188 (2007) 19-24.

[38] L. Qian, Z.L. Du, S.Y. Yang, Z.S. Jin. Raman-study of titania nanotube by soft chemical-process, J. Mol. Struct. 749 (2005) 103-107.

[39] V.A. Alves, R.Q. Reis, I.C.B. Santos, D.G. Souza, T. de F. Gonçalves, M.A. Pereira-da-Silva, A. Rossi, L.A. da Silva. In situ impedance spectroscopy study of the electrochemical corrosion of $\mathrm{Ti}$ and $\mathrm{Ti}-6 \mathrm{Al}-4 \mathrm{~V}$ in simulated body fluid at $25^{\circ} \mathrm{C}$ and $37^{\circ} \mathrm{C}$, Corrosion Sci. 51 (2009) 2473-2482.

[40] D. P. Oyarzún, R. Córdova, O. E. Linarez Pérez, E. Muñoz, R. Henríquez, M. López Teijelo, H. Gómez. Morphological, electrochemical and photoelectrochemical characterization of nanotubular $\mathrm{TiO}_{2}$ synthetized electrochemically from different electrolytes, J. Solid State Electrochem. 15 (2011) 2265-2275.

[41] G. J. Brug, A. L. G. van den Eeden, M. Sluyters-Rehbach, J. H. Sluyters. The analysis of electrode impedances complicated by the presence of a constant phase element, J. Electroanal. Chem. 176 (1984) 275-295.

[42] B. Hirschorn, M.E. Orazem, B. Tribollet, V. Vivier, I. Frateur, M. Musiani. Determination of effective capacitance and film thickness from constantphase-element parameters, Electrochim. Acta 55 (2010) 6218-6227.

[43] R.M. Fernández-Domene, R. Sánchez-Tovar, C. Escrivà-Cerdán, R. LeivaGarcía, J. García-Antón. Study of Passive Films Formed on AISI 316L 
Stainless Steel in Non-Polluted and Underwater-Volcano-Polluted Seawater, Corrosion Sci. 70 (2014) 390-401.

[44] A. G. Muñoz. Semiconducting properties of self-organized TiO2 nanotubes, Electrochim. Acta 52 (2007) 4167-4176.

[45] R. van de Krol, A. Goossens, J. Schoonman. Spatial Extent of Lithium Intercalation in Anatase $\mathrm{TiO}_{2}$, J. Phys. Chem. B 103 (1999) 7151-7159.

[46] Bard, A. J.; Faulkner, L. R. Electrochemical Methods, Wiley: New York (1980).

[47] Morrison, S. R. Electrochemistry of Semiconductor and Oxidized Metal Electrodes, Plenum Press: New York (1980).

[48] L. Aïnouche, L. Hamadou, A. Kadri, N. Benbrahim, D. Bradai. Interfacial Barrier Layer Properties of Three Generations of $\mathrm{TiO}_{2}$ Nanotube Arrays, Electrochim. Acta 133 (2014) 597-609.

[49] A. Hagfeldt, H. Lindström, S. Södergren, Sten-Eric Lindquist. Photoelectrochemical studies of colloidal $\mathrm{TiO}_{2}$ films: The effect of oxygen studied by photocurrent transients, J. Electroanal. Chem. 381 (1995) 39-46.

[50] M. Radecka, M. Rekas, A. Trenczek-Zajac, K. Zakrzewska. Importance of the band gap energy and flat band potential for application of modified $\mathrm{TiO}_{2}$ photoanodes in water photolysis, J. Power Sources 181 (2008) 46-55.

[51] M. Radecka, M.Wierzbicka, S.Komornicki, M. Rekas. Influence of $\mathrm{Cr}$ on photoelectrochemical properties of $\mathrm{TiO}_{2}$ thin films, Phys. B 348 (2004) 160168.

[52] P. Xiao, D. Liu, B. Batalla Garcia, S. Sepehri, Y. Zhang, G. Cao. Electrochemical and photoelectrical properties of titania nanotube arrays annealed in different gases, Sensor Actuat. B-Chem. 134 (2008) 367-372.

\section{Tables captions}

Table 1. Values of the equivalent circuit parameters for the different samples anodized at $\operatorname{Re}=0, \operatorname{Re}=200, \operatorname{Re}=400$ and $\operatorname{Re}=600$, without and with $\mathrm{Li}^{+}$-doping $(\mathrm{D})$. 
Table 2. Values of the donor density $\left(N_{D}\right)$ and flatband potential $\left(U_{F B}\right)$ for the different samples anodized at $\operatorname{Re}=0, \operatorname{Re}=200, \operatorname{Re}=400$ and $\operatorname{Re}=600$, without and with $\mathrm{Li}^{+}$-doping (D).

\section{Figures captions}

Figure 1. Current density transients obtained during the potentiostatic anodization of $\mathrm{Ti}$ at $55 \mathrm{~V}$ at different Reynolds number $(\operatorname{Re}=0, \operatorname{Re}=200, \operatorname{Re}=400$ and $\operatorname{Re}=600)$.

Figure 2. (a, b) FE-SEM images of the top-view of the $\mathrm{TiO}_{2} \mathrm{NTs}_{\text {anodized at } \mathrm{Re}=600}$ and the initiation layer; (c) the cross sectional view of the NTs anodized at $\operatorname{Re}=600$; (d) length of the nanotubes vs. Reynolds number.

Figure 3. FE-SEM images of the initiation layer at (a) $\operatorname{Re}=0$, (b) $\operatorname{Re}=200$, (c) $\operatorname{Re}=$ 400 and (d) $\operatorname{Re}=600$.

Figure 4. FE-SEM images of the pores of the initiation layer for the samples anodized at (a) $\operatorname{Re}=0$ and (b) $\operatorname{Re}=200$; (c) pore size of the initiation layer vs. Reynolds number; (d) wall thickness of the nanotubes vs. Reynolds number.

Figure 5. Raman confocal laser spectra of the as-prepared and annealed at $450{ }^{\circ} \mathrm{C}$

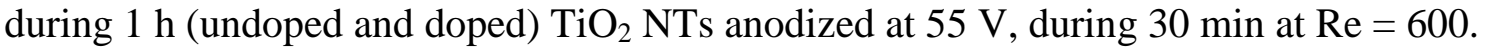


Figure 6. Experimental Nyquist (a), Bode-phase (b) and Bode-modulus (c) plots for the samples anodized at $\operatorname{Re}=0, \operatorname{Re}=200, \operatorname{Re}=400$ and $\mathrm{Re}=600$, with and without $\mathrm{Li}^{+}$doping; (d) electrical equivalent circuit used to simulate experimental EIS data.

Figure 7. Mott Schottky plots, obtained at a frequency of $10 \mathrm{kHz}$, of the undoped and doped nanotubes anodized at $55 \mathrm{~V}$, during $30 \mathrm{~min}$ at $\mathrm{Re}=0, \mathrm{Re}=200, \mathrm{Re}=400$ and $\mathrm{Re}$ $=600$.

Figure 8. (a) Photocurrent transient vs. potential curves of the samples anodized at $\mathrm{Re}=$ $0, \operatorname{Re}=200, \operatorname{Re}=400$ and $\operatorname{Re}=600$ with and without $\mathrm{Li}^{+}$-doping under $\mathrm{AM} 1.5$ illumination; (b) photocurrent densities vs potential registers carried out under AM 1.5 for two $\mathrm{TiO}_{2}$ nanotubes of the same length ( 6.2 microns) anodized in ethylene glycol/water/NH4F electrolytes at $\operatorname{Re}=0$ and $\operatorname{Re}=600$; (c) photostability experiments carried out under $\mathrm{AM} 1.5$ illumination at $0.55 \mathrm{~V}_{\mathrm{Ag} / \mathrm{AgCl}}$ of the samples anodized at $\mathrm{Re}=$ $0, \operatorname{Re}=200, \operatorname{Re}=400$ and $\operatorname{Re}=600$ with and without $\mathrm{Li}^{+}$-doping; (c) synergistic effect between the influence of hydrodynamic condition and $\mathrm{Li}^{+}$intercalation for different hydrodynamic conditions. 
Graphical Abstract (for review)
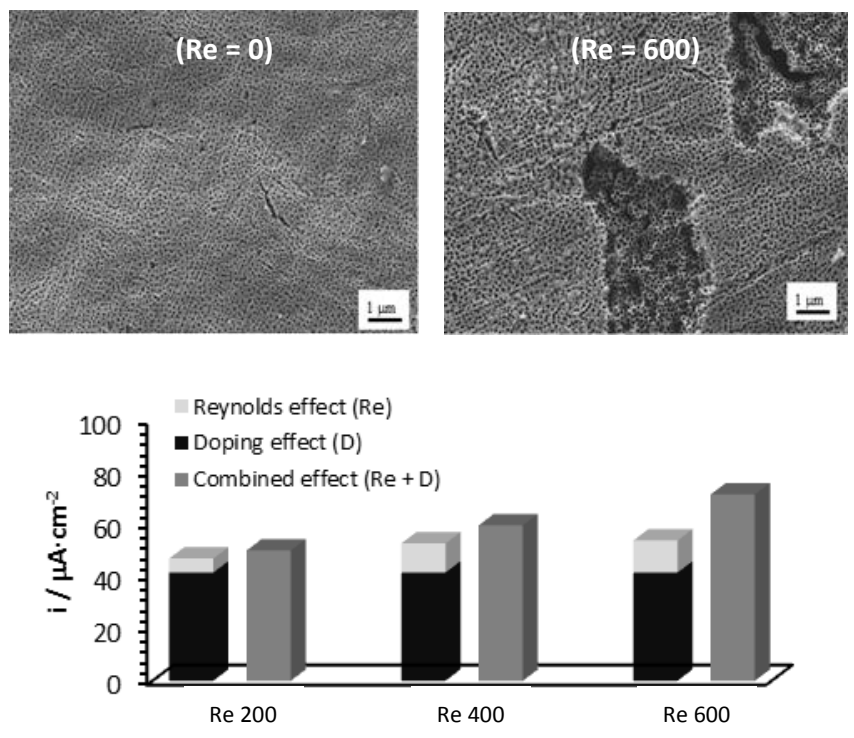

There is a synergistic effect between Reynolds number and $\mathrm{Li}^{+}$intercalation on $\mathrm{TiO}_{2}$ nanotubes for hydrogen production by means of photoelectrochemical water splitting. 
Hydrodynamic conditions during anodization remove part of the initiation layer

Hydrodynamic conditions during anodization led to higher photocurrent densities

The conductivity of the NTs increases with $\mathrm{Li}^{+}$intercalation

There is a synergistic effect among the hydrodynamic conditions and $\mathrm{Li}+$ intercalation

Doped nanotubes were stable in the test electrolyte under illumination 


\begin{tabular}{|c|c|c|c|c|c|c|c|c|}
\hline $\boldsymbol{R e}$ & $R_{S} / \Omega \mathrm{cm}^{2}$ & $C_{1} / \mu F \mathrm{~cm}-2$ & $\alpha_{1}$ & $R_{1} / k \Omega \mathrm{cm} 2$ & $C_{2} / \mu \mathrm{F} \mathrm{cm}^{-2}$ & $\alpha_{2}$ & $R_{2} / \mathrm{k} \Omega \mathrm{cm}^{2}$ & $\chi^{2}\left(\mathbf{x 1 0 ^ { - 3 }}\right)$ \\
\hline 0 & $38 \pm 4$ & $106 \pm 14$ & $0.68 \pm 0.03$ & $5.7 \pm 1.8$ & $1690 \pm 78$ & $0.98 \pm 0.02$ & $78.3 \pm 21$ & 5.3 \\
\hline 200 & $39 \pm 3$ & $279 \pm 11$ & $0.63 \pm 0.04$ & $5.1 \pm 1.3$ & $1903 \pm 84$ & $0.95 \pm 0.01$ & $39.4 \pm 23$ & 9.6 \\
\hline 400 & $42 \pm 5$ & $475 \pm 17$ & $0.56 \pm 0.08$ & $4.4 \pm 1.5$ & $1942 \pm 101$ & $0.95 \pm 0.03$ & $24.8 \pm 12$ & 8.5 \\
\hline 600 & $34 \pm 7$ & $132 \pm 18$ & $0.74 \pm 0.07$ & $2.5 \pm 1.0$ & $2399 \pm 97$ & $0.97 \pm 0.04$ & $38.4 \pm 11$ & 8.0 \\
\hline $0-\mathrm{D}$ & $32 \pm 3$ & $12413 \pm 52$ & $0.91 \pm 0.03$ & $1.9 \pm 0.7$ & $3360 \pm 132$ & $0.98 \pm 0.02$ & $18.3 \pm 8$ & 7.4 \\
\hline $200-\mathrm{D}$ & $32 \pm 4$ & $4560 \pm 97$ & $0.88 \pm 0.05$ & $1.7 \pm 0.4$ & $3394 \pm 112$ & $0.95 \pm 0.02$ & $36.2 \pm 12$ & 2.3 \\
\hline $400-\mathrm{D}$ & $36 \pm 5$ & $5865 \pm 63$ & $0.87 \pm 0.06$ & $1.4 \pm 0.5$ & $3900 \pm 168$ & $0.95 \pm 0.04$ & $31.9 \pm 13$ & 3.2 \\
\hline $600-\mathrm{D}$ & $27 \pm 8$ & $6655 \pm 75$ & $0.86 \pm 0.04$ & $1.0 \pm 0.4$ & $4942 \pm 150$ & $0.89 \pm 0.03$ & $28.0 \pm 9$ & 3.1 \\
\hline
\end{tabular}


Table 2

\begin{tabular}{|c|c|c|}
\hline $\boldsymbol{R e}$ & $\boldsymbol{N}_{\boldsymbol{D}}\left(\times \mathbf{1 0}^{\mathbf{1 9}} \mathbf{c m}^{\mathbf{- 3}}\right)$ & $\boldsymbol{U}_{\boldsymbol{F} \boldsymbol{B}} / \mathbf{V} \mathbf{~ v s}(\mathbf{A g} / \mathbf{A g C l})$ \\
\hline 0 & $1.8 \pm 0.3$ & $-0.19 \pm 0.05$ \\
\hline 200 & $2.1 \pm 0.3$ & $-0.10 \pm 0.03$ \\
\hline 400 & $3.9 \pm 0.5$ & $-0.09 \pm 0.05$ \\
\hline 600 & $3.6 \pm 0.4$ & $-0.09 \pm 0.02$ \\
\hline & & \\
\hline 0 - Doped & $390 \pm 10$ & $-1.58 \pm 0.09$ \\
\hline 200 - Doped & $107 \pm 9$ & $-0.70 \pm 0.08$ \\
\hline 400 - Doped & $192 \pm 12$ & $-1.08 \pm 0.03$ \\
\hline 600 - Doped & $278 \pm 11$ & $-1.06 \pm 0.09$ \\
\hline
\end{tabular}




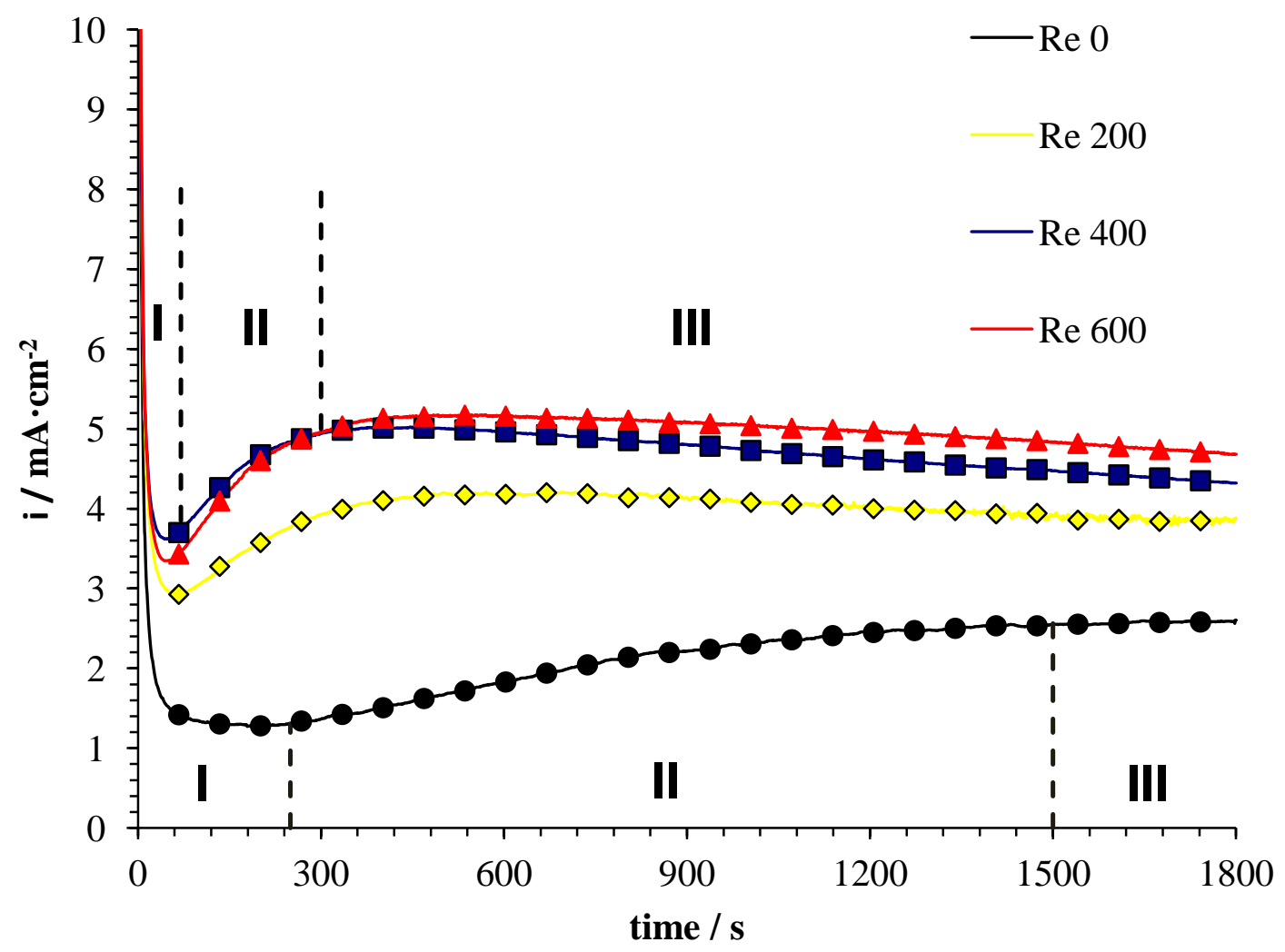



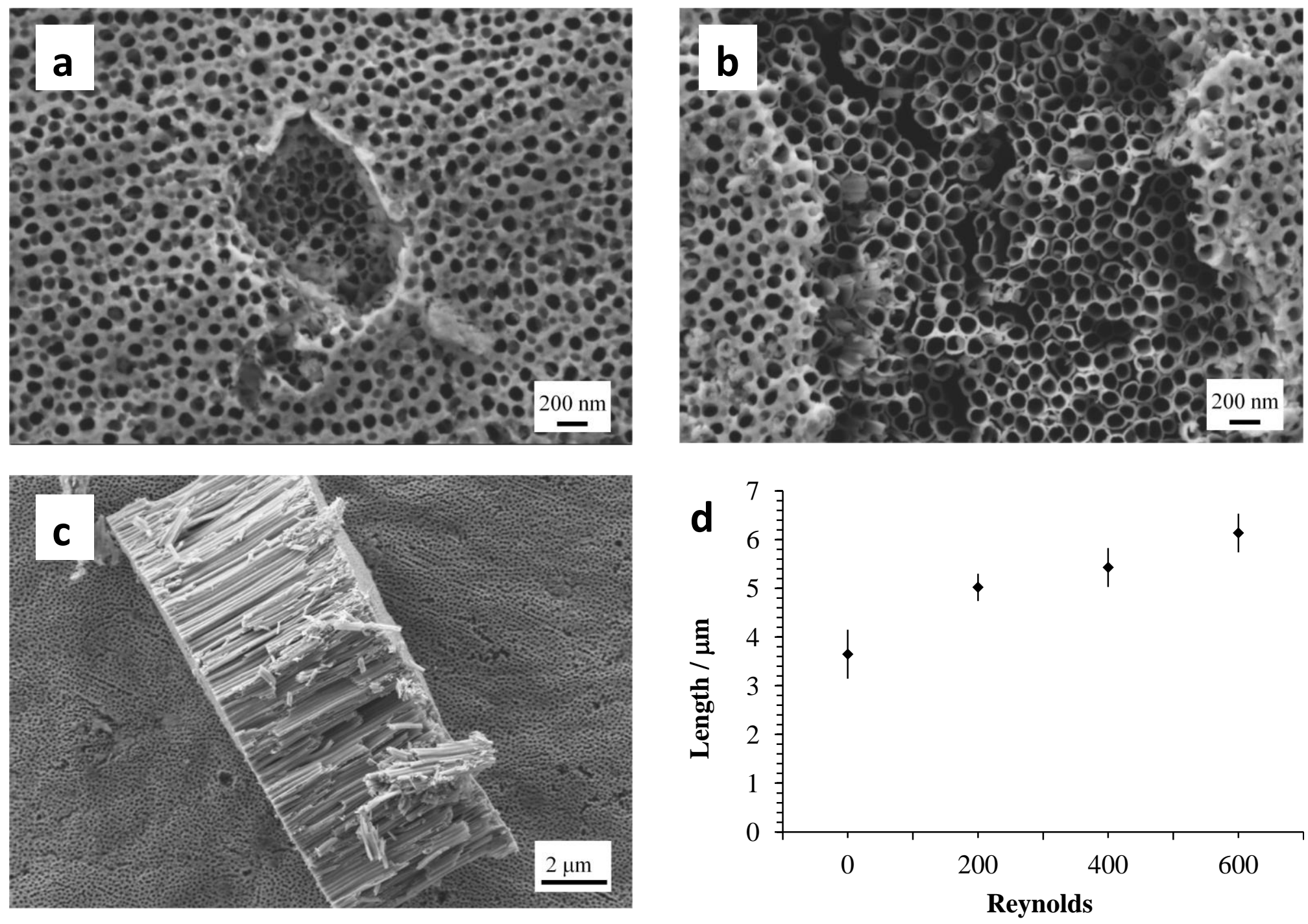

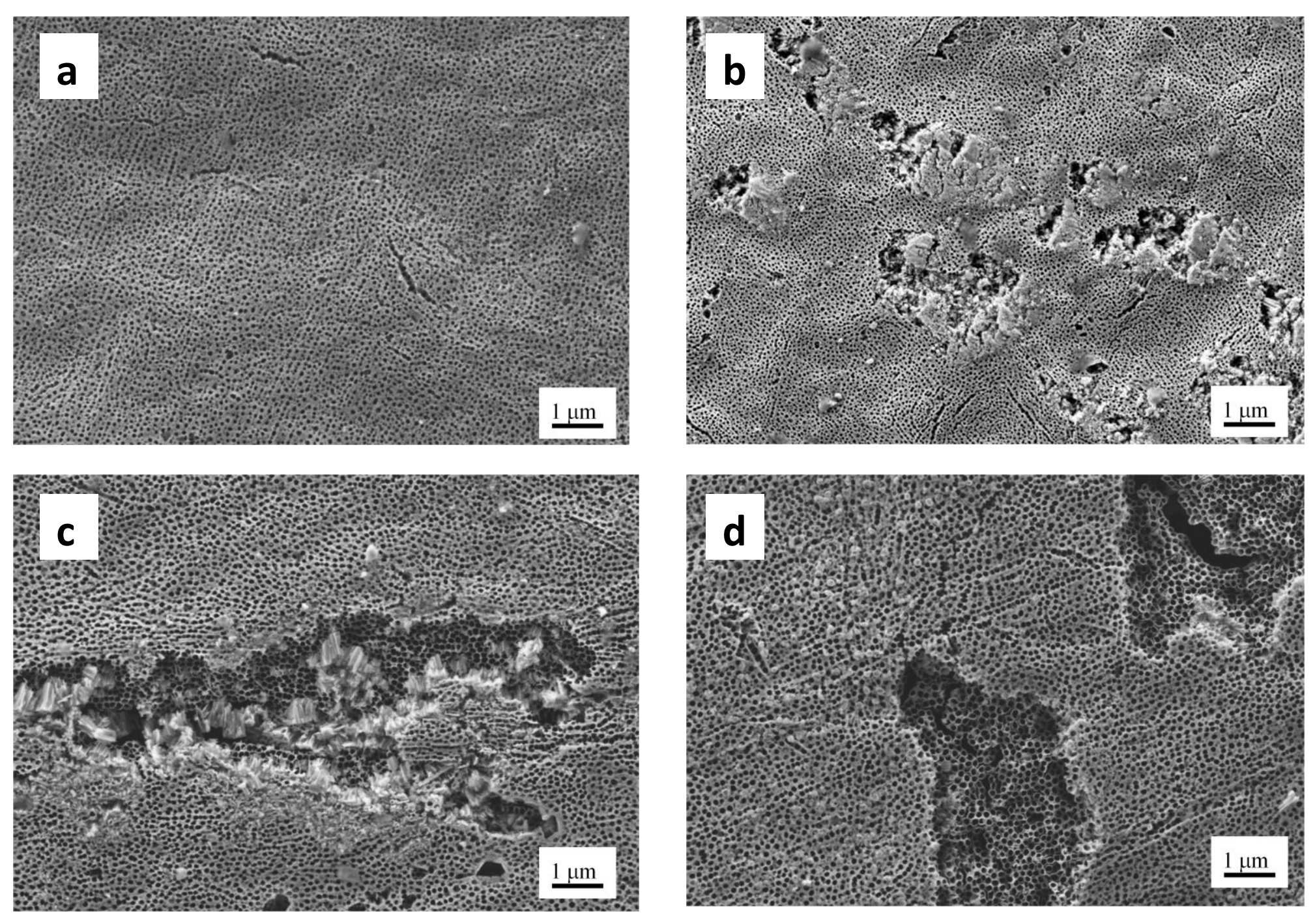

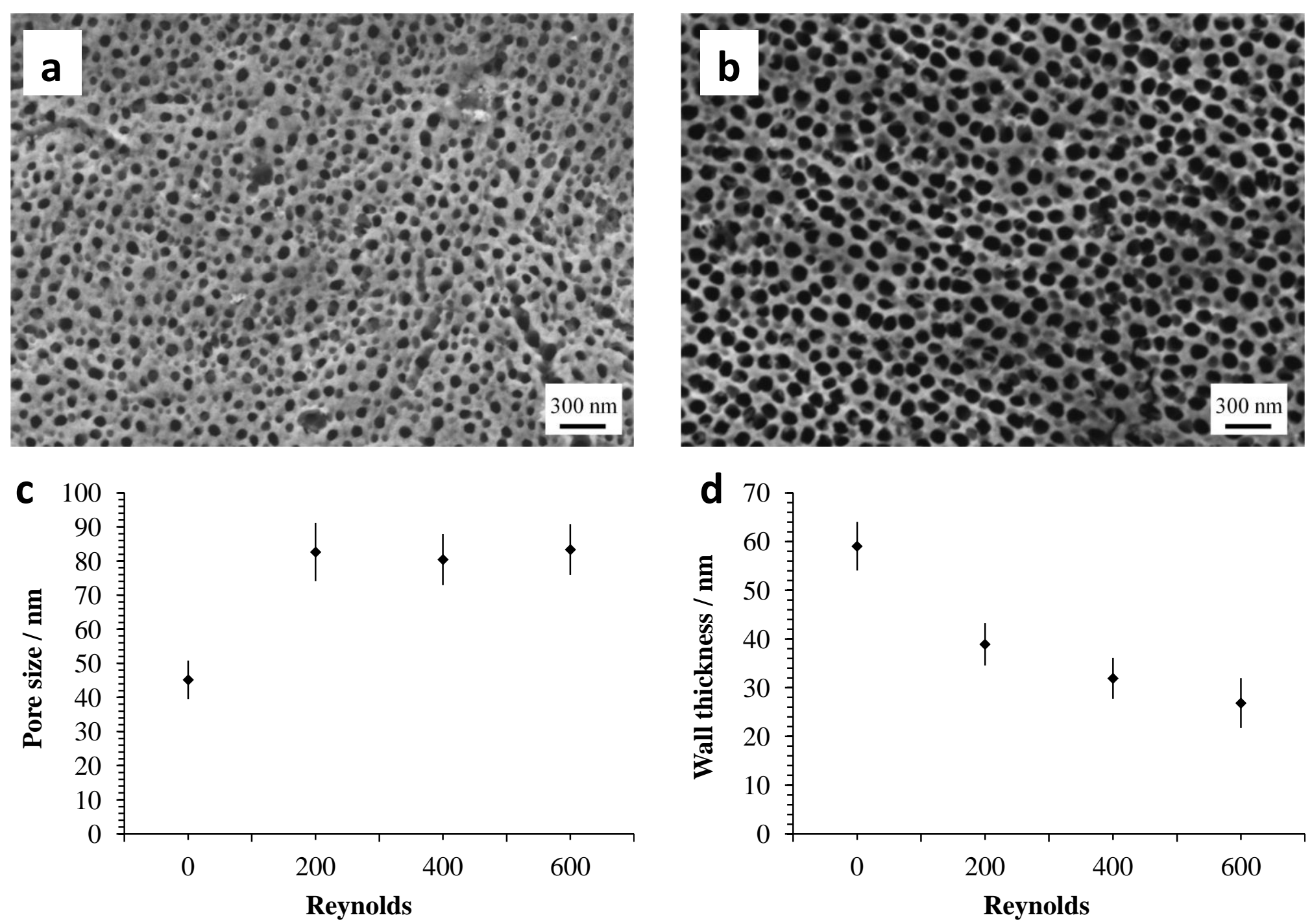
Figure 5

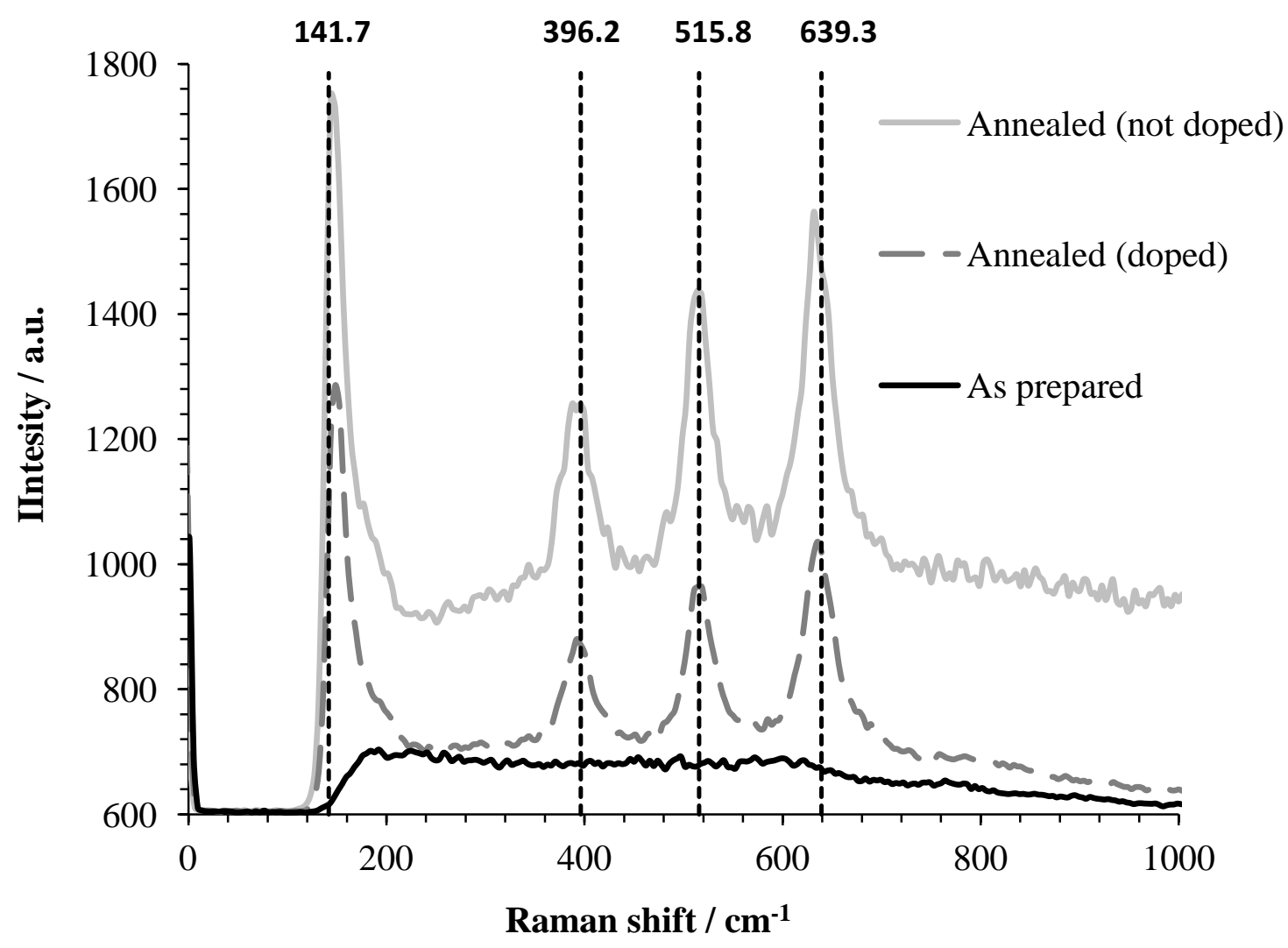


a
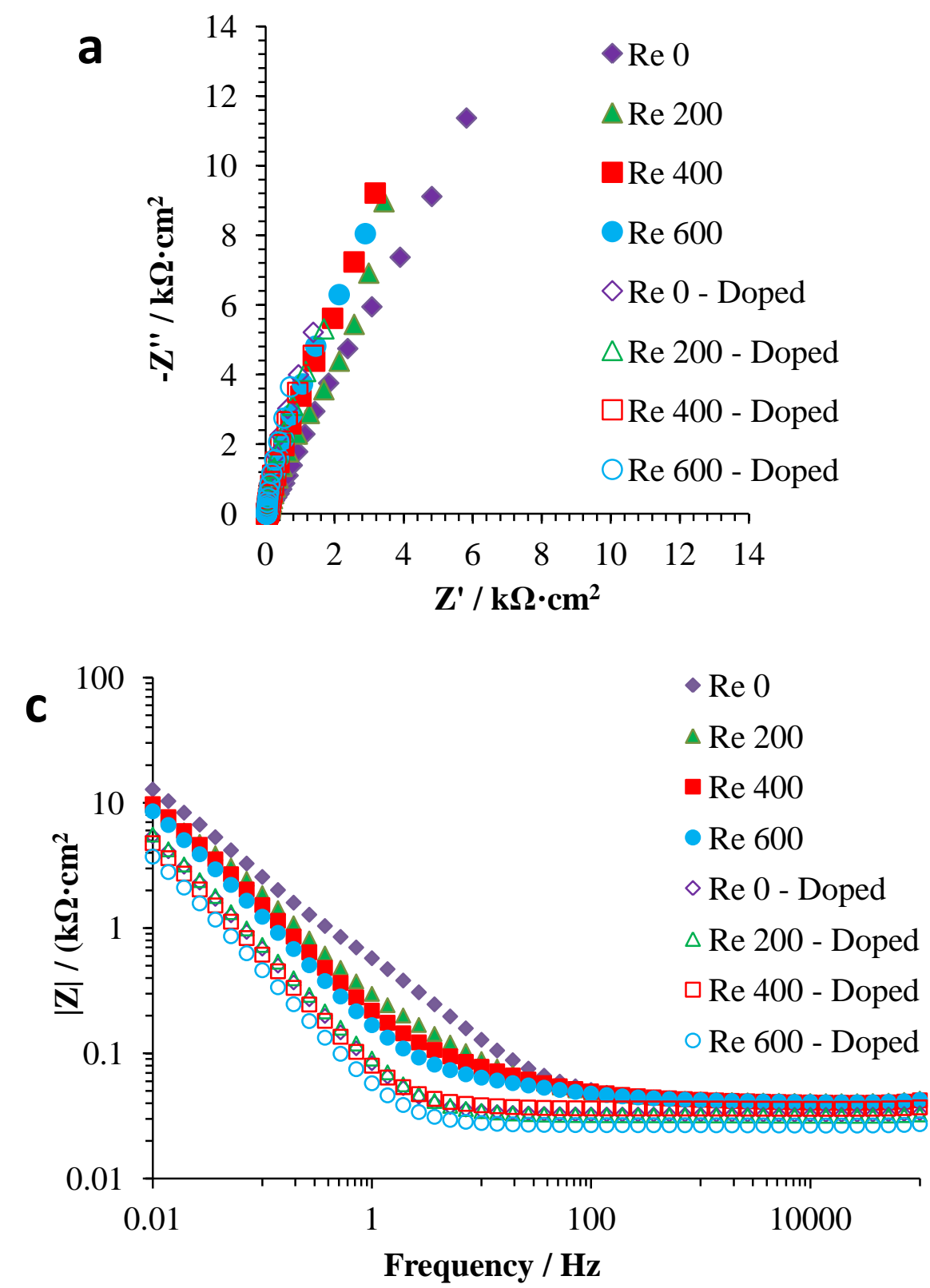

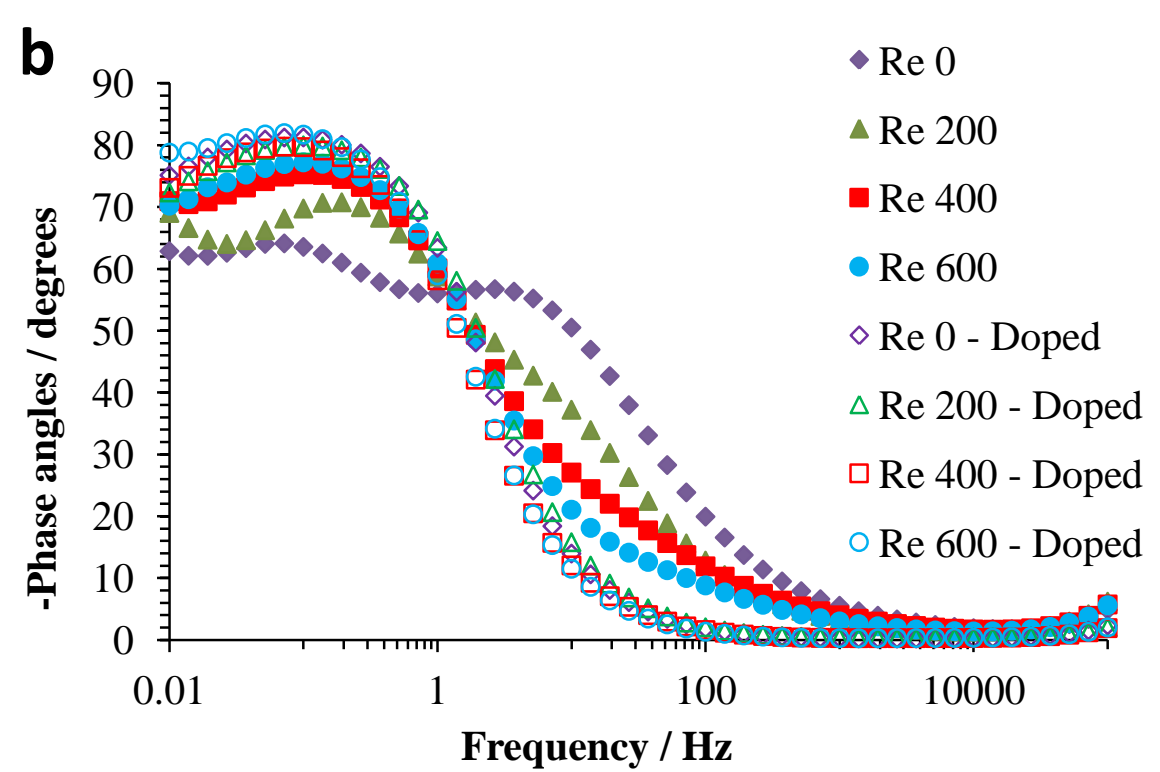

d

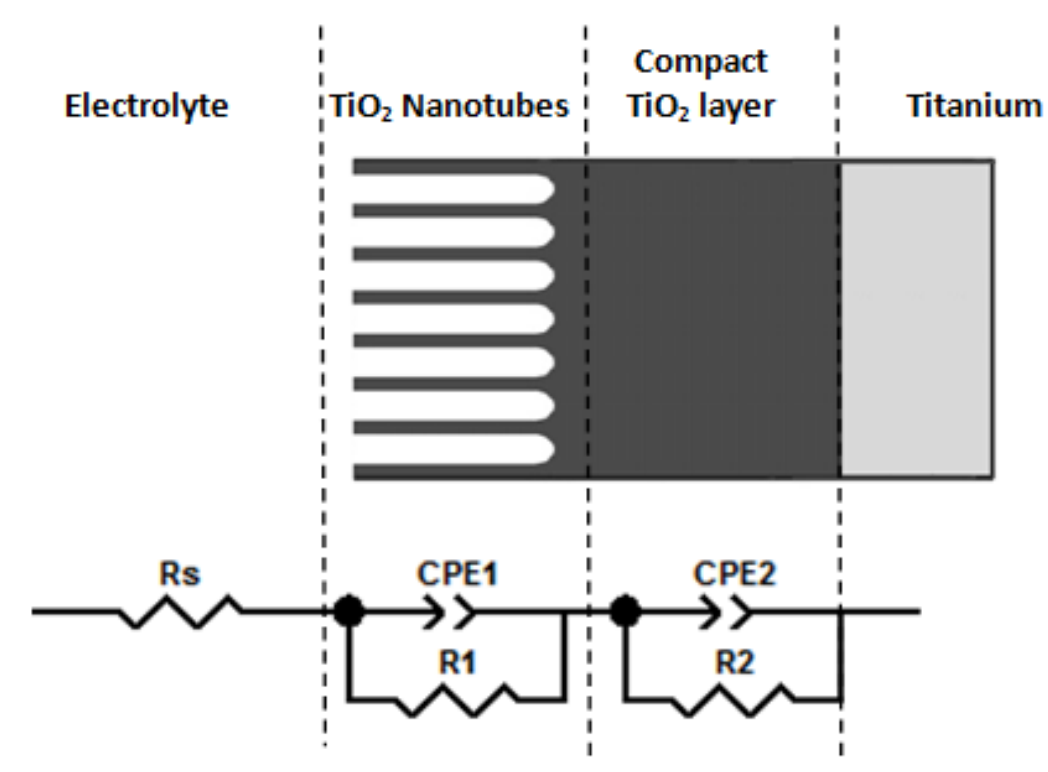



Figure 7

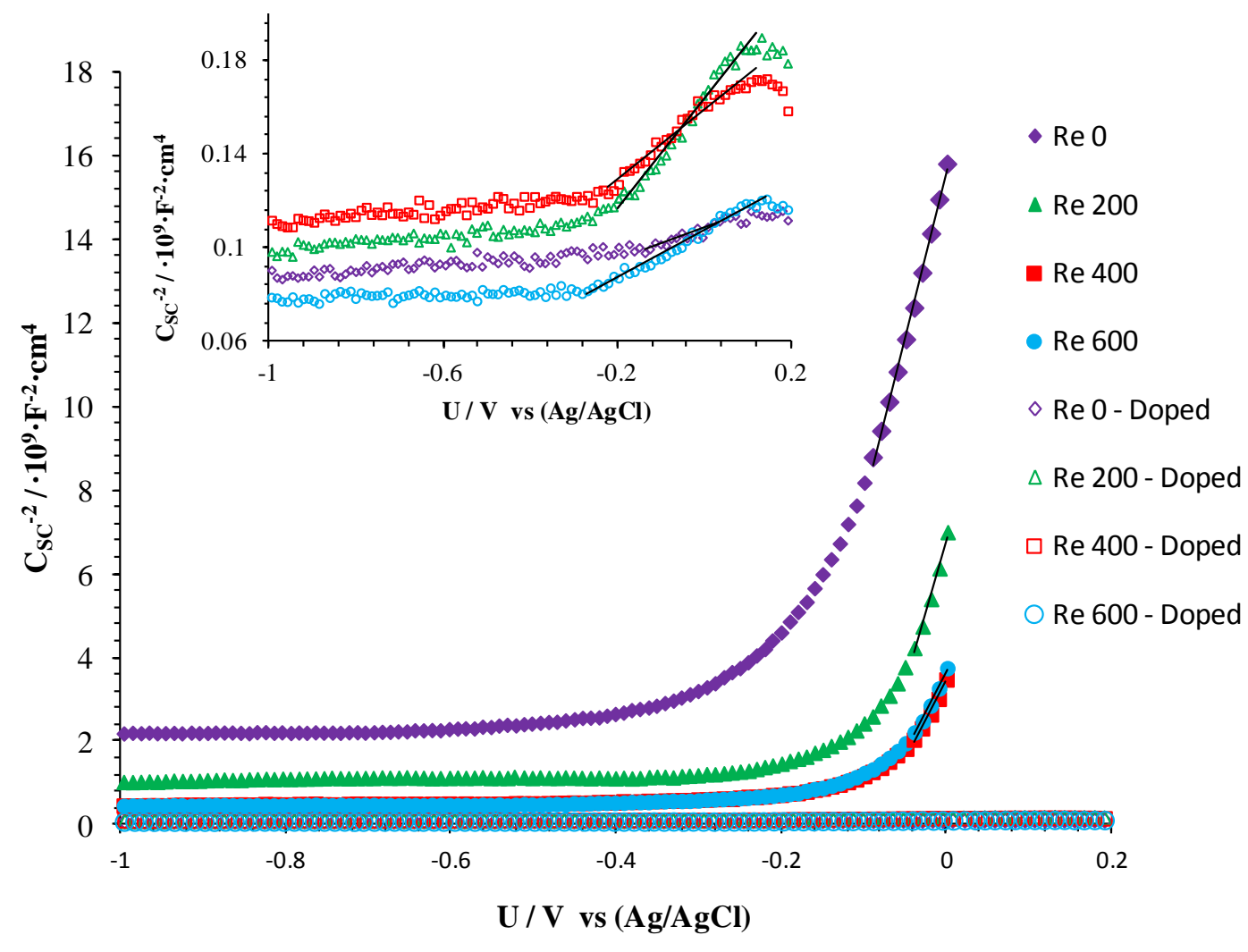



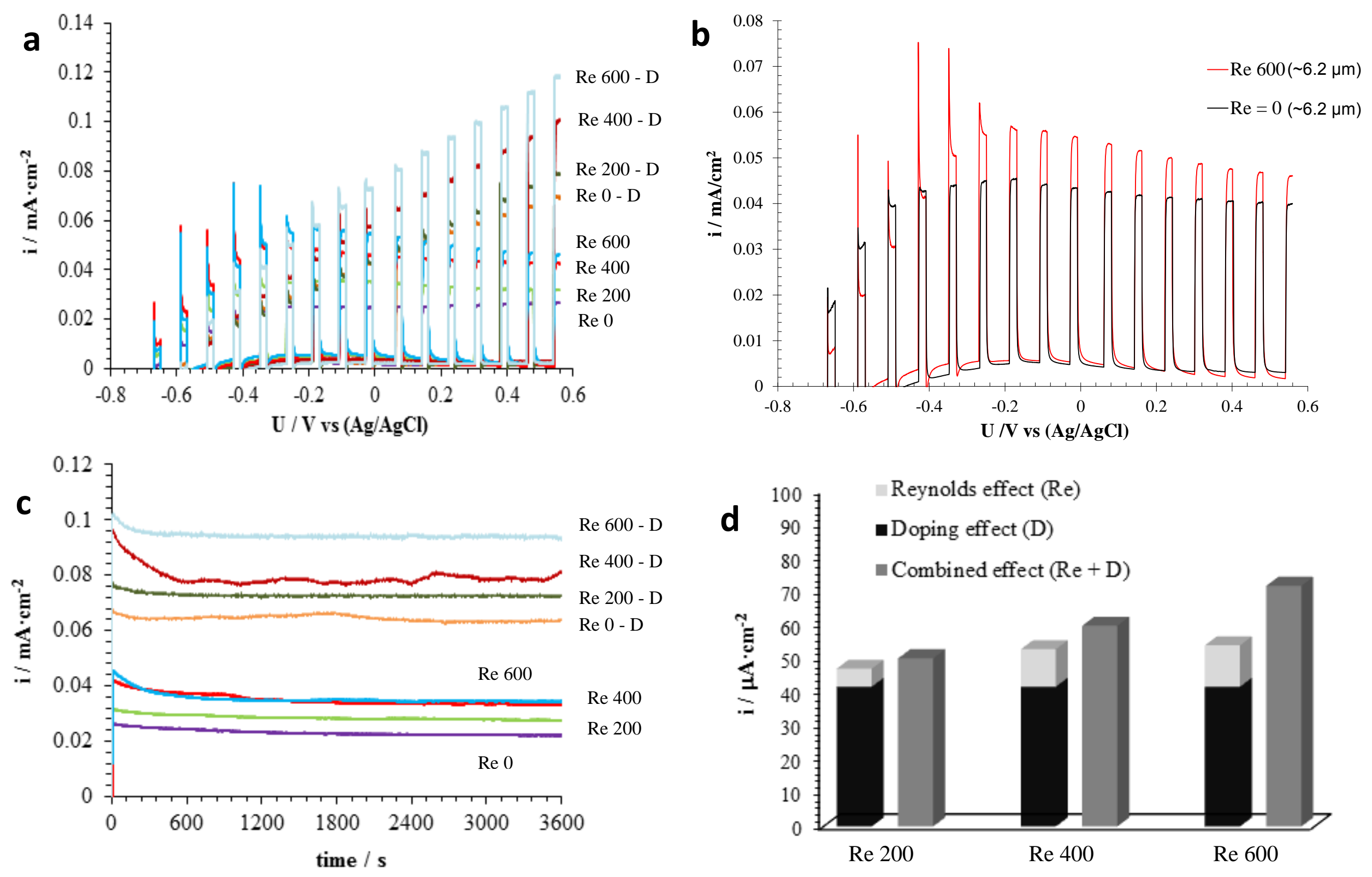